\title{
An Assessment of Primary Immunization and Factors Affecting Coverage - A Study on Hospitalised Children in Meghalaya
}

\author{
Jaideep V. Patel*, Santanu Deb, Palash R. Gogoi, Prasenjit Paul, Sabrina Yesmin, Lima Sangla, Pramod Paharia
}

*Corresponding author: Dr. Jaideep Vilas Patel

Abstract

Introduction: The need of the vaccines is felt the most in India, which accounts for $20 \%$ of the world's child population, and responsible for $24 \%$ of all under-five deaths globally. There are pockets of low immunization coverage areas even after putting so many efforts by Government of India for full immunization coverage which means there are many barriers to achieve the desired results. The present study focuses on finding prevalence of fully immunized, partially immunized or un-immunization status as well as those barriers so that a way out to full immunization coverage can be obtained. Aim: To find out the primary immunization coverage status and factors associated with incomplete immunization in first year of life in hospitalized children between 1 to 5 years of age. Materials and Methods: This is a hospital-based cross-sectional study involving 92 children admitted in tertiary care teaching hospital of Meghalaya, India for the calendar year 2019. An interviewer-administered structured questionnaire constructed from a review of available literature on immunization coverage and influencing factors in immunization coverage was used to obtain the required data. Results: 92 cases were enrolled in the study. Out of total cases, 63(68.5\%) were fully immunized, 18(19.6\%) were partially immunized and 11(12\%) were unimmunized. $27(29.3 \%)$. Females were $27(29.3 \%)$ and males $65(70.6 \%)(\mathrm{p}=0.04)$. Full primary immunization status was highest $(70.6 \%)$ when distance of nearest health centre was closer to residence $(10 \mathrm{~km})(\mathrm{p}=0.64)$, when maternal age was between 20-35 years, with class 1 socioeconomic status (Revised BG Prasad) $(79.2 \%)(p=0.049)$, with Urban residents $(77.8 \%)(\mathrm{p}=0.8)$, with joint family $(73.1 \%)(\mathrm{p}=0.04)$. Reason for drop out from full primary immunization was highest due to lack of knowledge of immunization schedule $(27.6 \%)$ followed by lack of awareness $(24.1 \%)$ and forgotten date (7.2\%). Conclusion: Fully immunized cases were more and has increased with the period of time as compared to NFHS4 data. Factors contributing in increasing full primary vaccination coverage in present study were closer distance of nearest health centre, matured maternal age group (20 to 35 years), educated mother, skilled mother, having good knowledge of vaccine, a smaller number of children with smaller family size, delivered in hospital, good socio-economic status, residing in urban area. Reason for drop out from full primary immunization was highest due to lack of knowledge of immunization schedule, lack of awareness and forgotten vaccination date.

Keywords: Immunization status, Immunization Coverage, Immunization status, Meghalaya, Northeast, Factors affecting immunization coverage.

Copyright (C) 2020 The Author(s): This is an open-access article distributed under the terms of the Creative Commons Attribution 4.0 International License (CC BY-NC 4.0) which permits unrestricted use, distribution, and reproduction in any medium for non-commercial use provided the original author and source are credited.

\section{INTRODUCTION}

According to the World Health Organization (WHO), "Health" is defined as a state of complete physical, mental, intellectual, social and emotional wellbeing and not merely the absence of disease or infirmity" [1]. Lack of health whether physical or psychological is not only harmful for the children but also harmful for nation. Out of many, immunization plays a very important role in maintaining child health. Considering this base, government is actively involved in implementing various immunization programs every year. Immunization is artificial way of getting infection by vaccine. The vaccine helps to stimulate the body's immune system of the child to make antibodies against viruses and bacteria. Normally, after a person fights off an infection, the immune system remembers and is better able to defeat that infection. Vaccines create the same beneficial responses without the illness [2]. Immunization is one of the most cost-effective health interventions known to mankind [3].

The need of the vaccines is felt the most in India, which accounts for $20 \%$ of the world's child population, and responsible for $24 \%$ of all under-five deaths globally. Government of India is allotting large part of its health budget in the immunization programs 
every year. Even after lot of initiatives regarding immunizations by government of India, dropping out from full immunization still remains as one of the important causes for occurrence of vaccine preventable diseases in the community [4].

There are many barriers to achieve the desired results. The present study focuses on finding these barriers (factors) associated with non-compliance of vaccination. It is important that people involved in the implementation of vaccination services should know the performance of vaccination program so that they can better design interventions that can help to improve and sustain vaccination coverage. Significant results will help in knowing the causes of ineffective vaccination and will help in effective planning and intervention to improve vaccination coverage.

\section{METHOD}

Hospital-based, cross-sectional study was conducted in Department of Paediatrics, Nazareth Hospital, Shillong from January 2019 to August 2019, with the aim to find out the primary immunization coverage status in first year of life, in the hospitalized children between 1 to 5 years of age and to find out factors associated with primary immunization coverage in same cases. Hospitalised children between 1 year to 5 years of age who have been born in Meghalaya and have been living in Meghalaya were participants.

A total of 92 consecutive cases admitted in pediatric ward of Nazareth Hospital fulfilling inclusion criteria were participants. It was commenced after obtaining approval from the Institutional Ethical Committee. An interviewer-administered structured questionnaire was used to obtain the required data. The questionnaire was constructed from a review of available literature on immunization coverage and influencing factors in immunization coverage. While making questionnaire local factors expected to influence immunization coverage were taken into consideration. Mother was asked to show immunization card, hospital record and then vaccines received was confirmed. In order to reduce bias for mother's history, remainder such as site of administration (whether it is taken as injection or orally, presence of scar) was included in questionnaire.

The outcome variables were tabulated in descriptive table and were subjected to the statistical analysis measures namely: Fisher's exact test for association between category of immunization and independent variables, Chi- Square test for association between category of immunization and independent variables, Frequency and percentage for analysis of demographic variables.

\section{RESULTS}

Out of the total 92 cases in the present study, majority of cases were male $(71 \%)$, of less than 1 year $(38 \%)$, of birth order less than $2(60 \%)$, delivered in Government hospital (48\%), residing in rural area (90\%), belonging to Nuclear family (72\%).

Table-1: Frequency and percentage distribution of demographic variables

\begin{tabular}{|c|c|c|c|}
\hline \multicolumn{2}{|l|}{ Variables } & No. of cases & $\%$ \\
\hline \multirow[t]{5}{*}{ Age in years } & 1 Year & 35 & $38.0 \%$ \\
\hline & 2 Years & 24 & $26.1 \%$ \\
\hline & 3 Years & 13 & $14.1 \%$ \\
\hline & 4 Years & 19 & $20.7 \%$ \\
\hline & 5 Years & 1 & $1.1 \%$ \\
\hline \multirow[t]{2}{*}{ Gender } & Male & 65 & $70.7 \%$ \\
\hline & Female & 27 & $29.3 \%$ \\
\hline \multirow[t]{3}{*}{ Nearest health facility } & $<5 \mathrm{KM}$ & 85 & $92.4 \%$ \\
\hline & $5-10 \mathrm{KM}$ & 3 & $3.3 \%$ \\
\hline & $>10 \mathrm{KM}$ & 4 & $4.3 \%$ \\
\hline \multirow[t]{4}{*}{ Maternal age at child birth } & $<20$ Years & 5 & $5.4 \%$ \\
\hline & 20-25 Years & 31 & $33.7 \%$ \\
\hline & 26-35 Years & 49 & $53.3 \%$ \\
\hline & $>35$ Years & 7 & $7.6 \%$ \\
\hline \multirow{5}{*}{ Maternal education } & Uneducated & 20 & $21.7 \%$ \\
\hline & Primary & 25 & $27.2 \%$ \\
\hline & Secondary & 35 & $38.0 \%$ \\
\hline & Higher secondary & 4 & $4.3 \%$ \\
\hline & Graduate & 8 & $8.7 \%$ \\
\hline \multirow[t]{5}{*}{ Maternal occupation } & Housewife & 76 & $82.6 \%$ \\
\hline & Skilled & 10 & $10.9 \%$ \\
\hline & Unskilled & 0 & $0.0 \%$ \\
\hline & Farmer & 2 & $2.2 \%$ \\
\hline & Business & 4 & $4.3 \%$ \\
\hline Marital status & Married & 92 & $100.0 \%$ \\
\hline
\end{tabular}




\begin{tabular}{|l|l|l|l|}
\hline \multirow{2}{*}{ Knowledge of mother } & Good & 68 & $73.9 \%$ \\
\cline { 2 - 4 } & Bad & 24 & $26.1 \%$ \\
\hline \multirow{3}{*}{ Place of vaccination } & Government centre & 84 & $91.3 \%$ \\
\cline { 2 - 4 } & Private centre & 8 & $8.7 \%$ \\
\hline \multirow{3}{*}{ Number of family members } & Joint & 26 & $28.3 \%$ \\
\cline { 2 - 4 } & Nuclear & 66 & $71.7 \%$ \\
\cline { 2 - 4 } & 55 & 43 & $46.7 \%$ \\
\hline \multirow{3}{*}{ Number of children } & $5-10$ & 44 & $47.8 \%$ \\
\cline { 2 - 4 } & $>10$ & 5 & $5.4 \%$ \\
\hline \multirow{3}{*}{ Place of delivery } & $<2$ & 52 & $56.5 \%$ \\
\cline { 2 - 4 } & $3-5$ & 39 & $42.4 \%$ \\
\cline { 2 - 4 } & $>5$ & 1 & $1.1 \%$ \\
\hline \multirow{2}{*}{ Place of residence } & Home delivery & 21 & $22.8 \%$ \\
\cline { 2 - 4 } & Government hospital delivery & 44 & $29.8 \%$ \\
\cline { 2 - 4 } & Private hospital delivery & 27 & $90.2 \%$ \\
\hline & Rural & 83 & $9.8 \%$ \\
\cline { 2 - 4 } & Urban & 9 & \\
\hline
\end{tabular}

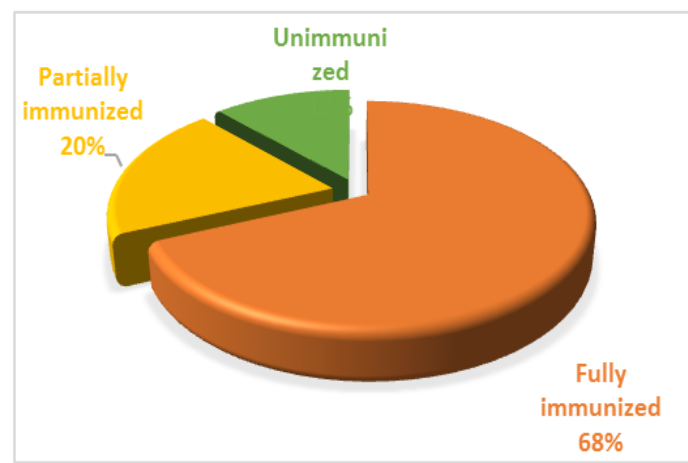

Fig-1: Distribution of cases of the present study on the basis of primary immunization status

In the present study, 63(68.5\%) were fully immunized, $18(19.6 \%)$ were partially immunized and $11(12 \%)$ were unimmunized (Figure-1). Female (70\%) was having higher percentage of full primary immunization as compared to male (68\%) (Figure-2).

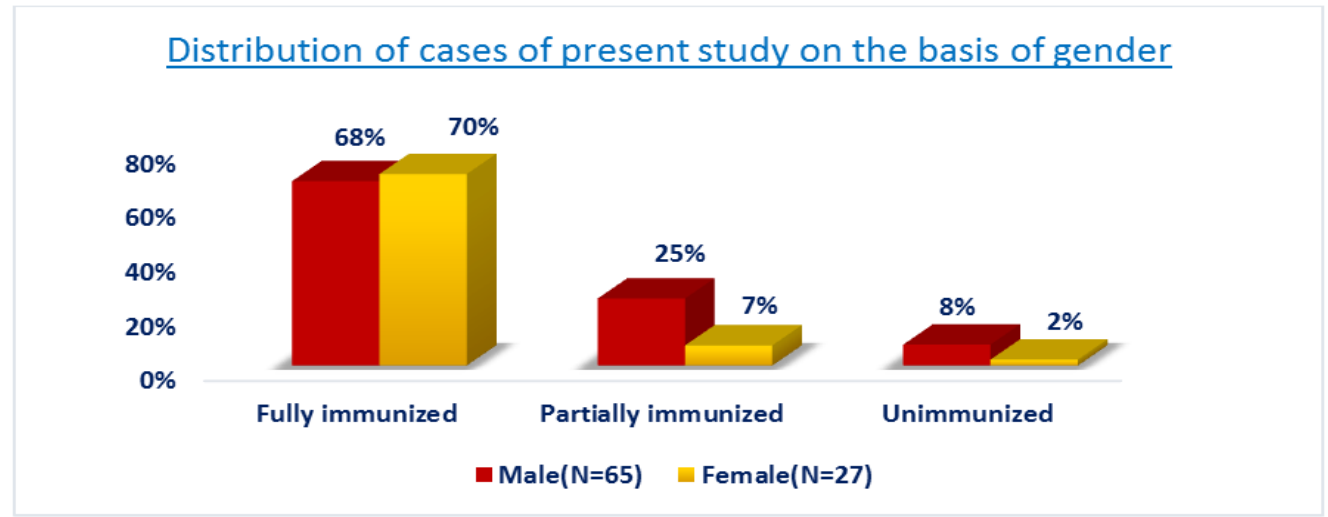

Fig-2: Distribution of cases of the present study on the basis of primary immunization status

Full primary immunization status was highest $(70.6 \%)$ when distance of nearest health centre was closer to residence, when maternal age was between 2025 years and 26-35 years, when education status was higher $(87.5 \%)$, for skilled mother $(80 \%)$. Mother of all the cases of present study were married. Full primary immunization status was highest $(75 \%)$ when maternal knowledge on vaccine was good and un-immunised status was highest $(25 \%)$ when maternal knowledge on vaccine was poor. Full immunization status was minimum $(52.4 \%)$ for cases which were delivered at home as compared to hospital delivered cases. Full primary immunization status was highest and equal $(69.2 \%)$ when number of children were less than 5. Full primary immunization status was highest $(79.2 \%)$ with class 1 of socioeconomic status. Full primary immunization status was highest $(77.8 \%)$ with Urban residents. Full primary immunization status was highest $(73.1 \%)$ with joint family. 
Table-2: Comparison of immunization status of cases in the present study on the basis of different variables

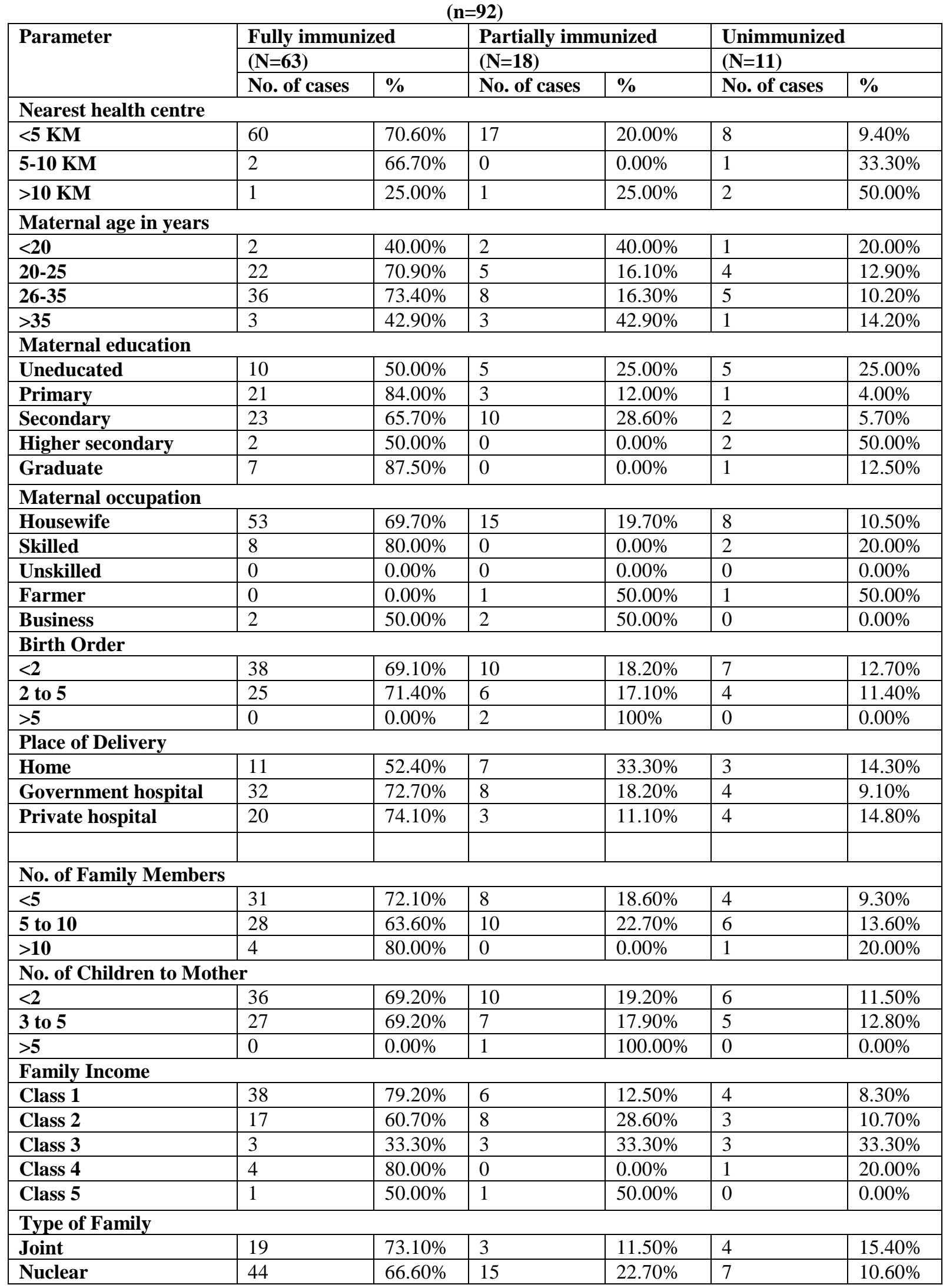

Reason for drop out from full primary immunization was highest due to lack of knowledge of immunization schedule (27.6\%) followed by lack of awareness $(24.1 \%)$ and forgotten date $(7.2 \%)$. 
Jaideep V. Patel et al., Sch J App Med Sci, October, 2020; 8(10): 2331-2336

\begin{tabular}{|l|l|l|}
\hline Reasons for drop out from vaccination & No. of cases & \% \\
\hline Lack of knowledge of immunization schedule & 8 & $27.6 \%$ \\
\hline Unwell child, immunization postponed & 3 & $10.3 \%$ \\
\hline Lack of health facility in nearby locality & 0 & $0.0 \%$ \\
\hline Lack of awareness & 7 & $24.1 \%$ \\
\hline Immunization has no benefit & 2 & $6.9 \%$ \\
\hline Fear of side effects & 1 & $3.4 \%$ \\
\hline Forgotten date & 5 & $17.2 \%$ \\
\hline Immunization is harmful & 0 & $0.0 \%$ \\
\hline No local health worker & 0 & $0.0 \%$ \\
\hline No vaccines availability at vaccination centre & 0 & $0.0 \%$ \\
\hline Adverse reaction to previous vaccine & 2 & $6.9 \%$ \\
\hline Culture taboo & 1 & $3.4 \%$ \\
\hline
\end{tabular}

\section{DiSCUSSION}

The present study has full immunization coverage nearly similar to NFHS 4-National and Meghalaya state data. However, more as compared to DLHS 4 data and study conducted by Kumar D et al., [5], in New Delhi. The probable reasons behind this increase in full primary immunization status in present study can be due to the difference in the years when these studies were undertaken, during these time gap there were tremendous advancement in social media, massive awareness programs and vaccination programs like Intensified Mission Indradhanush which was initiated and monitored by Government of India. Majority of the mothers were educated and were aware of the vaccine preventable diseases.

In the present study, female was having higher percentage of full primary immunization as compared to male. The probable reason behind this female predominance could be due to the presence of matrilineal society in Meghalaya, hence female children tend to get more medical attention. Similarly, an all India study conducted by Singh PK et al., [6] found that North- Eastern states of India had higher full immunization in females as compared to males, whereas rest of the states showed male predominance.

Among the mother of children who had full primary vaccination coverage, $89 \%$ were educated, $75 \%$ had good knowledge on vaccination, majority were aged between 20-35 years and were skilled workers. Mother's education, maternal knowledge on vaccination, matured age of mother and maternal occupation has a significant positive influence towards full vaccination coverage. Educated and skilled mothers had higher income and majority were belonging to higher socioeconomic class. Full primary immunization status was highest $(79 \%)$ with higher socio-economic class. In low socio-economic class where, primary essential needs get priority, obtaining health care becomes difficult task. Mother of all the cases of this study were married. Nothing can be concluded in present study on this variable.
In the present study, it was found that full primary immunization status was highest with Joint family $(73 \%)$, smaller family size $(72 \%)$, urban residents $(77.8 \%)$ and when birth order was $<2$ which may be due to more attention and caring provided to first born children. However, it was found in most of the studies that Nuclear family had higher full immunization status like Paul A et al., [7] in North 24 Parganas of West Bengal. This confliction with our study may be because of Joint family culture being common in the area of study. With joint family there are more members who contributes in family income as well as more members who can take care of its children. Urban area has easy accessibility to health care centre as well as multiple options are available as compared to rural area.

In the present study, reason for drop out from full primary immunization was maximum due to lack of knowledge of immunization schedule followed by lack of awareness and forgotten date, unwell child and postponement of immunization.

\section{Conclusion}

In the present study, fully immunized cases were more and has increased with the period of time. Factors contributing in increasing full primary vaccination coverage in present study were closer distance of nearest health centre, matured maternal age group (20 to 35 years), educated mother, skilled mother, having good knowledge of vaccine, a smaller number of children with smaller family size, delivered in hospital, good socio-economic status, residing in urban area. Reason for drop out from full primary immunization was highest due to lack of knowledge of immunization schedule, lack of awareness and forgotten vaccination date.

\section{DECLARATIONS}

\section{Author's Contribution}

Principal Investigator: Dr Jaideep V. Patel Co Investigators: Dr Santanu Deb, Dr Palash R. Gogoi, Dr Prasenjit Paul, Dr Sabrina Yesmin, Dr Lima Sangla and 
Dr Pramod Paharia revised the manuscript and assisted in the study design.

Sources of funding: NIL

Conflicts of interest: NIL

Financial associations: NIL

Ethical approval: The study was approved by institutional ethics committee.

\section{REFERENCES}

1. Child Health-Definition [Internet]. 2007 [cited 2018 Dec 26]. Available from: http://www.azftf.gov/WhoWeAre/Board/Documen ts/Program Committee/Health/January 13, 2011 Meeting - Health/07 Child Health Definition Recommendation.pdf

2. Gurang S. Child Health Care System in North East India with Special Reference to Sikkim [Internet]. Sikkim; [cited 2018 Dec 5]. Available from: http://14.139.206.50:8080/jspui/bitstream/1/4735/ 1/Sumitra Gurung-MPhil Economics.pdf
3. Bansal CP, Agarwal R, Yewale VN, Gupta S. Guidebook on Immunization. 2013;

4. NFHS-4 [Internet]. Meghalaya; 2016 [cited 2018 Dec 28]. Available from: http://rchiips.org/NFHS/pdf/NFHS4/ML_FactShee t.pdf

5. Kumar D, Aggarwal A, Gomber S. Immunization status of children admitted to a tertiary-care hospital of North India: Reasons for partial immunization or non-immunization. J Heal Popul Nutr. 2010; 28(3):300-4.

6. Singh PK. Trends in Child Immunization across Geographical Regions in India: Focus on UrbanRural and Gender Differentials. PLoS One. 2013 Sep 4; 8(9).

7. Paul A. Immunization Coverage and Its Determinants among Children in a Rural Community: A Case Study at Haroa CD Block North 24 Parganas, West Bengal [Internet]. Vol. 5. [cited 2019 Dec 10]. Available from: http://ijrar.com/ 